\title{
Pregnant women's knowledge, perceived severity, and perceived controllability of the COVID-19 and their associations with emotional and behavioral reactions: A cross-sectional study
}

\section{Somayyeh Khazaeian}

Pregnancy Health Center, Department of Midwifery and counseling, Zahedan University of Medical Sciences, Zahedan, Iran https://orcid.org/0000-0002-5596-4937

\section{Safoura Khazaeian}

Department of Obstetrics and Gynecology, School of Medicine, Zahedan University of Medical Sciences, Zahedan, Iran https://orcid.org/0000-0002-4981-5417

\section{Azita Fathnezhad-kazemi ( $\square$ afnkazemi@gmail.com )}

Department of Midwifery, Faculty of Nursing and Midwifery Islamic Azad University, Tabriz branch, Tabriz, Iran https://orcid.org/0000-0002-3601-9892

\section{Research Article}

Keywords: knowledge, emotional, self-care, anxiety, Covid-19, pregnancy

Posted Date: December 22nd, 2020

DOI: https://doi.org/10.21203/rs.3.rs-132425/v1

License: (c) (1) This work is licensed under a Creative Commons Attribution 4.0 International License.

Read Full License 


\section{Abstract}

Background: COVID-19 pandemic has caused a tidal wave of anxiety and stress among Iranians, especially pregnant women. In order to control this unpleasant situation, it is indispensable to examine such issues as the level of Knowledge, emotions, and health behaviors. This study aimed to assess the association between knowledge, perceived severity, and perceived controllability of covid-19 with emotional and behavioral reactions in pregnant women.

Methods: This cross-sectional study was performed on 440 pregnant women who were selected via the multistage sampling method from four different cities of Sistan-Baluchestan province, Iran. Data were collected using demographic-obstetrics characteristics form, as well as the questionnaires of knowledge, perceived severity, and perceived controllability of the COVID-19, health anxiety, and self-care.

Results: Based on the results, self-care was positively correlated with knowledge, perceived severity, and perceived controllability of the COVID-19. Nonetheless, health anxiety had a significant and inverse association with knowledge and perceived controllability, while there was a positive and significant correlation between perceived severity and health anxiety. Based on linear regression, three variables of knowledge, perceived severity, and perceived controllability of the COVID-19 could explain 46.3 and $17.5 \%$ of variations in self-care and health anxiety, respectively. Finally, people with higher education and knowledge obtained higher scores on self-care and lower scores on health anxiety.

Conclusion: As evidenced by the obtained results, it is suggested that due to the critical importance of prenatal care, managers, and health officials promote the use of such methods as telehealth and homebased caregivers, especially in areas with inadequate access to health care. In so doing, the pregnant women can be followed up and receive medical care devoid of any stress and anxiety and without a physical presence in healthcare centers.

\section{Background}

Severe acute respiratory syndrome coronavirus 2 (SARS-CoV-2), the virus responsible for COVID-19, is a professional pathogen easily transmitted from one person or place to another [1,2]. Due to its detrimental effects, this disease is recognized as one of the most devastating disasters the world has ever faced. The clinical spectrum of this disease ranges from asymptomatic or mild disease $(81 \%)$ to respiratory failure requiring mechanical ventilation (14\%) and critical condition with systemic manifestations (5\%) [3]. Nonetheless, the negative effect of this disease is thought to depend in large part on the human immune response [4].

Pregnant women run a higher risk of severe viral respiratory infections due to physiologic changes in immune and cardiopulmonary systems [5]. On the other hand, dramatic physical and psychological pregnancy-related changes increase their vulnerability to different life stressors [6]; therefore, they are more susceptible to anxiety and stress, compared to other people [7]. Due to the emergency of COVID-19, the 
adoption of preventive and protective measures, such as social distancing and movement restrictions, has overshadowed various aspects of people's lives and affected the emotional and behavioral reactions of individuals [8]. According to reports, emotional reactions, such as stress and anxiety, have increased in people from all walks of society, especially the high-risk groups [9]. Moreover, the implementation of quarantine measures and fear of getting infected with coronavirus has discouraged people from referring to health centers [10]. The novelty of coronavirus has prompted people to search for information on different news channels; consequently, all the aforementioned issues can affect self-care behaviors [11, 12]. Based on the matters referred, pregnant women are more likely to be exposed to this disease due to their special conditions [13]. Moreover, they may show different responses in order to achieve the desired pregnancy and fetal health outcomes [14]. It is an agreed-upon fact that performing self-care behaviors can help achieve favorable pregnancy outcomes [10]. Nevertheless, based on related studies, the adoption of self-care behaviors can be affected by various factors. For instance, low levels of disease perception have led to a reduction in self-care behaviors in pregnant women [15]. On the other hand, the available evidence confirms that the perceived severity of the problems has caused patients to adopt higher levels of self-care behaviors [16, 17]. Based on the existing literature, individuals' evaluation of the situation, knowledge, perceived severity, and perceived controllability of disease can play a peculiar role in emotional and behavioral reactions, especially health behaviors, to control epidemics [18]. In addition, they can be effective in the management of stressful and worrying situations [19].

There is not adequate information on knowledge, perceived severity, and perceived controllability of COVID-19 and their impacts on health anxiety and self-care of women, especially pregnant women. Perceived severity, knowledge, and behaviors of people towards different diseases can vary in different age groups, life periods, and places. Therefore, it is necessary to assess the effect of knowledge, perceived severity, and behavioral control on the disease and its consequences, especially in vulnerable pregnant women. According to statistics, the maternal mortality rate is very high in Sistan and Baluchestan province in southeastern Iran, and the mean score of pregnancy self-care was reported as $44 \%$ in this province. Moreover, there is not enough information about public knowledge about COVID-19 and its effect on the emotions and behavior of people, especially pregnant women. Furthermore, peoples' evaluation of the current situation and making behavioral responses to public health concerns is of particular importance for proper planning and intervention by stakeholders and policymakers. Therefore, the present study was designed to achieve the following goals:

1- Assessing the level of public knowledge, as well as the perceived severity, and perceived behavioral control in COVID-19 situation

2- Evaluating the relationship of public knowledge, perceived severity, and perceived behavioral control in COVID-19 situation with health anxiety and self-care in pregnant women

\section{Methods}

\section{Study Design and Participants}


This cross-sectional study was conducted during the COVID-19 pandemic in Sistan-baluchestan province, Iran, between August 16- September 30, 2020. Inclusion criteria included the Iranian nationality, Zahedan, Khash, Mirjaveh, and Saravan residency, singleton pregnancy, ability to read and write in Persian, age range of 18-40 years, pregnancy over 10 weeks, no experience of severe psychological crises over the past six months (declared by the participants), no known medical disorders or problems, and obstetrics-related risk factors during and before pregnancy based on medical files approved by the physician or midwife at the center and not having COVID-19 disease. The exclusion criteria were lack of willingness to participate in the study and incomplete questionnaires.

\section{Sample size and sampling method}

To obtain the research objectives, the maximum sample size was calculated as the sample size based on the first objective of the research. Therefore, the sample size for the self-care scale was calculated at 40 cases based on the study conducted by Momeni Javid et al. [20] with an acceptable error of 0.05 around the mean $(m=71.9), 95 \%$ confidence interval, $90 \%$ statistical power, and standard deviation of 11.48 . Moreover, based on the study conducted by Li et al.,[21] the sample size for the scale of knowledge was calculated at 50 cases with an acceptable error of $0.05,95 \%$ confidence interval, $90 \%$ statistical power around the mean $(m=3.56)$ and standard deviation of $0.61,25$ subjects for the scale of perceived severity around the mean $(\mathrm{m}=4.09)$ and the standard deviation of 0.51 , and 78 cases for the scale of perceived behavioral control around that mean $(m=3.25)$ and the standard deviation of 0.72 . Furthermore, the sample size for the scale of health anxiety was calculated at 267 cases considering the rate of health anxiety $(50.7 \%)$ and frequency $(12 \%)$ reported in the study conducted by Corbet [9]. Finally, in the present study, the sample size was estimated at 400 subjects based on the maximum sample size obtained from the level of health anxiety and considering the design effect of 1.5 . Finally, considering $10 \%$ sample attrition, 440 subjects were entered into the study.

$$
N=\frac{\left(Z 1-\frac{\alpha}{2}\right)^{2} \times \rho(1-\rho)}{d^{2}}
$$

Sampling was conducted in the healthcare centers. Most of the pregnant women have health records in these healthcare centers and posts. For sampling, a two-stage cluster sampling was carried out. So that, each of the cities covered by the University of Medical Sciences were divided into four clusters: north, south, east and west. Then, from each cluster, according to the number of pregnant women, relative coverage is given to each city. One or two centers were randomly selected using a randomizer software (www.random.org). 8 centers from Zahedan, 4 centers from Khash, 3 centers from Saravan and one center from Mirjaveh were randomly selected. Then, a list of all pregnant women at each center was extracted from the health records and the samples was randomly selected from the ordered numbers. Afterward, Using the phone number registered in each record, the researcher called the potential participants and invited them to participate in the study and if needed the researcher visited their home. The eligible 
participants were provided with full explanations about the study objectives and procedures. Also, informed consent obtained before collecting information, and emphasized the importance of honest answers to the questionnaire, and asked them to complete the anonymous questionnaires in a private room. A number of participants were likely to be illiterate, so the questionnaires were completed by the researcher in order for the data collection method to be the same for all individuals. Sampling was continued until the total sample size was reached.

\section{Scales and data collection}

Quantitative data was collected using 5 questioners, including:

\section{Sociodemographic and Obstetrics Characteristics Form:}

consisted of questions about the women's and husband's ages, the women and husband's education, the women and husband's Employment status, number of pregnancies, number of deliveries, gestational age.

\section{Knowledge of COVID-19 Questionnaire}

This 12-item questionnaire assesses people's knowledge of COVID-19. The responses are rated on a 3point Likert scale, $2=y e s, 1=\mid$ have no idea, and $0=$ no, with higher scores signifying a higher level of knowledge.

\section{Perceived Severity of Covid-19 Questionnaire}

The perceived severity questionnaire consists of 5 items is rated on a 5-point Likert scale (strongly agree= $5, \ldots$ strongly disagree $=1$ ), with higher scores indicating higher perceived severity.

\section{Perceived Behavioral Control of Covid-19 Questionnaire}

This 11-item questionnaire was rated on a 5-point Likert scale (strongly agree $=5$, agree $=4$, don't know $=3$, disagree $=2$ and strongly disagree $=1$ ). Higher scores were suggestive of a higher perceived behavioral control.

\section{Anxiety Health questionnaire}

This 18-item standard questionnaire was scored based on a 4-point Likert scale (not at all $=0$, sometimes $=1$, often $=2$, and always $=3$ ), with higher scores signifying higher physical anxiety. This questionnaire was evaluated by Salkowski and Warwick (2002), and its Cronbach's alpha coefficient was reported as $0.71-0.92[22]$.

\section{Pregnancy Self-Care questionnaire}

This questionnaire was designed by Momeni-javid in Iran [20]. It consists of 13 questions that are rated on a 4-degree Likert scale (never $=1$, sometimes $=2$, most of the time $=3$, and always $=4$ ). The minimum and maximum scores are 1 to 52 . 
The three questionnaires of COVID-19 knowledge, perceived severity, and perceived behavioral control were designed based on the study conducted by Zang et al. [21]. To confirm the content validity of these questionnaires, they were provided to five experts in the field of midwifery and health education, and the necessary modifications were made.

Reliability of the questionnaire was determined by using test-retest method after conducting a pilot study on 20 pregnant women. Both of the reproducibility (ICC = Intraclass Correlation Coefficient) and internal consistency (Cronbach's alpha coefficient) were determined for all questionnaires. ICC (confidence interval) and Cronbach's alpha coefficient for knowledge, perceived severity and perceived behavioral control of COVID-19 were $0.97(0.94-0.98)$ and $0.8,0.91(0.89-0.93)$ and $0.86,0.87(0.85-0.9)$ and 0.91 , respectively. ICC (confidence interval) and Cronbach's alpha coefficient for Anxiety Health and Pregnancy Self-Care were $0.98(0.97-0.99)$ and $0.95,0.93(0.91-0.95)$ and 0.79 .

\section{Data analysis}

SPSS-22 software is used to analyze the quantitative data. Scoring of sociodemographic, knowledge, perceived severity and perceived behavioral control of covid-19, Anxiety Health and Pregnancy Self-Care questionnaires were described by frequency (percent), as well as mean (Standard Deviation) if the data are normally distributed. The association between Variables were determined using the independent test, ANOVA and Pearson correlation tests in the bivariate analysis. Then, independent variables, with $P \leq 0.05$ on bivariate tests inserted into the multivariate linear regression model (enter method). The normality of quantitative data was measured based on Kolmogorov-Smirnov test, all of which were normal. All tests were 2-sided.

\section{Results}

\section{Sociodemographic and Obstetrics Variables}

The present study was conducted on 440 pregnant women. The mean (SD) of maternal age, gestational age, and gravida were reported as $29.32(6.26), 23(7.88), 3.29(1.76)$, respectively.

The majority of participants (48.4\%) were within the age range of 25-34 years and in the second trimester of pregnancy. Nearly three-quarters of the subjects had a high school education, and more than threequarters of cases were housewives. As reported, $38.4 \%$ of the subjects had just received primary care, and $81.64 \%$ of cases stated that fear of being infected with coronavirus discouraged them from seeking medical care.

Data analysis disclosed that except for maternal age, gestational age, and spouse's occupation, demographic-obstetrics characteristics were significantly correlated with self-care and health anxiety (Table 1). Mean(SD) of knowledge, perceived severity, and perceived behavioral control were obtained at 14.15(5.08), 17.08(3.32), and 40.50(10.42), respectively. In addition, the mean score of self-care and health anxiety were reported as $31.25(8.59)$ and $32.72(7.64)$. Pearson correlation test demonstrated that self-care 
was positively correlated with knowledge, perceived severity, and perceived behavioral control, and this relationship was strong, weak, and moderate, respectively.

On the other hand, the obtained results pointed to the significant but inverse association of knowledge with perceived behavioral control and health anxiety. In this regard, the score of health anxiety decreased by an increase in knowledge and perceived behavioral control, and the mentioned variables had a moderate and weak relationship with health anxiety, respectively. Nonetheless, there was a significant positive correlation between health anxiety and perceived severity. That is to say, health anxiety increased with the elevation of the perceived severity of the disease $(P<0.01)$; however, the association was very weak (See Table 2).

Using univariate linear regression, firstly, in model 1 the effect of knowledge, perceived severity, and perceived behavioral control on self-were was separately examined, and knowledge showed the strongest relationship rendering a correlation coefficient of 0.620 . In other words, one standard deviation increase in the knowledge variable leads to a 0.620 standard deviation increase in self-care score. In model 2, the variables of knowledge, perceived severity, and perceived behavioral control were simultaneously entered into the model. A relatively strong correlation was observed between these three variables and self-care score $(R=0.683)$, and $46.3 \%$ of the total changes in self-care score were related to these three variables $\left(R^{2} \operatorname{adj}=0.463\right)$.

In this model, knowledge $(\beta=0.494)$ and perceived severity $(\beta=0.110)$ had the highest and lowest regression effect on self-care scores. In regression model 3 , in addition to the three main research variables, the variables in Table 1 which were significantly associated with self-care were simultaneously entered into the model. The results of this model illustrated that $62.9 \%$ of the total changes in self-care score depended on these nine variables $\left(R^{2} a d j=0.629\right)$. The two variables of knowledge and participants' education were effective on self-care score $(P<0.01)$.

Moreover, based on higher regression coefficient $(\beta=0.753)$, education had a higher regression effect on self-care score, compared to knowledge. This signifies that one standard deviation increase in the education variable leads to a 0.753 standard deviation increase in self-care score. Nonetheless, one standard deviation increase in the knowledge variable results in a 0.330 standard deviation increase in self-care score (See Table 3). Similar to self-care, the regression model was also used for health anxiety scores.

Firstly, the effect of knowledge, perceived severity, and perceived behavioral control on health anxiety was separately examined in model 1 , and knowledge obtained the highest correlation coefficient $(\beta=0.325)$. In Model 2, the variables of knowledge, perceived severity, and perceived behavioral control were simultaneously entered into the model, and a moderate correlation was detected between these three variables and health anxiety score $(R=0.425)$. The results showed that these three variables were significantly correlated with health anxiety. In this model, knowledge also obtained the highest regression coefficient $(\beta=-0.275)$. Since this relationship was negative, it can be said that one standard deviation increase in knowledge results in a 0.275 standard deviation decrease in health anxiety score. 
In model 3 , the sum of three main variables and six significant variables in Table 1 were simultaneously entered into the model. The output of the model demonstrated that $0.29 .7 \%$ of the total changes in health anxiety score were related to these nine variables $\left(R^{2} a d j=0.297\right)$, and these nine variables predict approximately $30 \%$ of the variance of health anxiety. In this model, except for education and knowledge, other variables had no effect on health anxiety $(P>0.01)$. The output of this model showed that one standard deviation increase in the education variable led to a 0.362 standard deviation decrease in health anxiety. Moreover, one standard deviation increase in the knowledge variable resulted in a 0.206 standard deviation decrease in health anxiety (Table 4).

\section{Discussion}

Pregnant women are very vulnerable to infectious diseases due to physiologic changes in the immune and cardiopulmonary systems. In addition, their concerns about fetal health put their health at greater risk [23]. Therefore, it is of utmost importance to assess the factors affecting women's health during pandemics in an attempt to minimize their morbidity [24]. Therefore, the present study examined the relationship of knowledge, perceived severity, and perceived behavioral control with self-care and health anxiety in pregnant women.

Based on linear regression, the variables of knowledge, perceived severity, perceived control, and education were predictive variables for self-care behaviors and health anxiety. The results of the present study showed that pregnant women had a moderate level of knowledge, perceived severity, and perceived controllability in COVID-19 situation. Similar results have been obtained in other studies. For instance, studies conducted in Turkey [25] and Bangladesh [11] reported low levels of knowledge among the participants. It can be attributed to the fact that COVID-19 is an emerging and unknown disease.

Nonetheless, it is required that people, especially high-risk groups, be provided with information by health care providers and through reliable news channels. On the other hand, the obtained data signified that the participants obtained low scores in self-care behaviors and health anxiety. The scores of self-care during pregnancy were very low in the current study, compared to previously conducted studies $[26,27]$. In the present study, although most of the participants (81.6\%) were in the second and third trimesters of pregnancy, the mean of prenatal care was very low during the COVID-19 pandemic.

Nevertheless, in the Millennium Development Goals, the World Health Organization highlighted the importance of prenatal care in reducing maternal and perinatal mortality, and WHO recommended that pregnant women should all receive at least five antenatal visits [28]. In the current study, $81.64 \%$ of women did not receive antenatal care since they were afraid of getting infected with coronavirus during hospital visits. This finding can be justified on the grounds that fear and worry inevitably increase during infectious disease outbreaks. Therefore, fear, worry, and subsequent negative emotions seem understandable in the midst of this worldwide pandemic [29, 30].

In the current study, the findings pointed to the direct relationship of self-care with knowledge, perceived severity, and perceived behavioral control. Self-care was higher in people with a higher level of knowledge, 
perceived severity, and perceived behavioral control. Among the mentioned variables, the level of knowledge showed the highest correlation with self-care. In the regression analysis in the final model, after entering the main variables along with demographic-midwifery variables, participants' educational level was the only variable that had a significant effect on increasing self-care.

It has been proven that knowledge is a prerequisite for preventive care ideas and behaviors, adopting a positive attitude, and promoting effective skills for the management of diseases [31]. The results of studies on influenza disclosed that pregnant women with low levels of education and little knowledge of the protective role of vaccines in the prevention of infection make less of an effort to receive vaccinations $[32,33]$. Other similar studies also demonstrated that people with low knowledge and low education level report poor personal hygiene habits [34] and self-care [35]. This finding is consistent with the results of the present study in which self-care improved with an increased level of education and knowledge.

Another finding of the current study denoted that perceived severity and perceived behavioral control in COVID-19 situation, along with knowledge, were significant predictors of self-care. As suggested by several studies, when people have a high disease perception, they are more likely to execute preventive measures against infectious diseases [36]. However, contrary to the results of the present study, Yıldırım et al. (2020) indicated that people with lower perceptions of disease severity exhibited more preventive behaviors [25]. These discrepancies can be attributed to demographic characteristics, gender, and even age.

Furthermore, people's weariness from observing preventive measures, such as frequent mask-wearing or hand-washing can reduce the level of self-care despite the high perception of disease severity [37]. High perceived disease severity and the absence of behavioral control can lead to an improper understanding of the current situation, as well as the adoption of ineffective and inappropriate strategies, which in turn, negatively affect self-care [38]. Nevertheless, in general, when people take threats seriously, they are more involved in protective measures. In the case of COVID-19, the perceived threat can also serve as a motivating factor for the execution of self-care behaviors [39].

Another finding of the present study was the significant relationship between health anxiety and the main variables of the study. This relationship was negative for knowledge and perceived behavioral control, while it was positive for perceived severity. In the final regression model, only the variables of maternal knowledge and education were effective in health anxiety so that health anxiety decreased by increasing maternal knowledge and education.

In their study, Shiina et al. (2020) reported that people with low levels of knowledge and education experienced less health anxiety. In addition, they exhibited less preventive behavior in crowded places [37]. Wirtz et al. (2019) found a positive correlation between knowledge and COVID-19 health anxiety. Furthermore, contrary to the results of the present study, they indicated that the presence of anxiety is useful for the adoption of preventive behaviors, although they have a complicated relationship [40]. As reported by other studies, the speed of disease transmission and media reports contribute to increasing physical anxiety and behavioral control [41, 42]. 
Nevertheless, it is very difficult to make a comparison between the findings of the present research and those reported by other studies since sample variations can affect the interpretation of the results. For example, these contradictions can be ascribed to performing studies on different populations, age groups, and occupations. In the present study, the participants were pregnant women most of whom were housewives. Therefore, their presence at home and less exposure to contaminated environments could contribute to their reduced anxiety despite high knowledge.

Another point worth noting is the health anxiety questionnaire which was used as the research instrument in the present study. Although this scale is a standard tool, it is not specifically designed for epidemics. The final finding was the positive and significant correlation between the perceived severity of the disease and health anxiety; however, this relationship was weak. Along the same lines, in their study, Tull et al. (2020) pointed out that health anxiety increases over time among people with a higher perception of disease severity [43]. These results support the hypothesis that the COVID-19 pandemic will increase health anxiety among people[44].

\section{Limitation}

The notable limitations of the present study included the research method which could not establish a cause and effect relationship. The second limitation was collecting data through self-reported questionnaires. Moreover, only pregnant women who were covered by university centers were included in the study, while some women may receive care from private centers, and this can affect generalizability. Finally, the sample size was unequally selected from different cities based on the population of each region; nonetheless, it may have affected the results.

\section{Conclusion}

The results of the present study which was conducted on pregnant women evidenced that the mean perinatal care was very low; moreover, the mean score of self-care behaviors was not favorable. As indicated by the results, knowledge, perceived severity, and perceived behavioral control, along with maternal education, were predictive factors for self-care behaviors and health anxiety. Therefore, it is suggested that due to the importance of prenatal care, managers, and health officials promote the use of such methods as telehealth and homebased caregivers, especially in areas with inadequate access to health care. In so doing, the pregnant women can be followed up and receive medical care devoid of any stress and anxiety and without a physical presence in healthcare centers. Consequently, perinatal care can be provided to protect maternal and neonatal health by early detection of pregnancy complications.

\section{List Of Abbreviations}

Covid-19: Coronavirus disease 19

WHO: World Health Organization

ICC: Intraclass Correlation Coefficient 


\section{Declarations}

\section{Ethics approval and consent to participate}

Written informed consent will be obtained from each participant. This study was approved by the Ethics Committee of the Zahedan Medical Sciences University, Iran (code number: IR.ZAUMS.REC.1399.238).

\section{Consent for publication}

Not applicable.

\section{Availability of data and materials}

The datasets used and/or analyzed during the current study are available

from the corresponding author on reasonable request.

\section{Competing interests}

The authors declare that they have no competing interests.

Funding: This study received no specific grant from any funding agency.

\section{Authors' contributions}

A. Fn-K developed the study concept. All authors contributed to the study design. Testing and data collection were performed by So.K and Sa.K. Data analysis and interpretation were performed by So.K and A. Fn-K. So.K and Sa.K drafted the manuscript, and A. Fn-K and So.K provided critical revisions. All authors approved the final version of the manuscript for submission.

\section{Acknowledgments}

We thank the women who participated in the study. We also appreciate the support

From the Zahedan University of Medical Sciences.

\section{Disclosure Statement}

No potential conflict of interest was reported by the authors

\section{References}

1. Alzamora MC, Paredes T, Caceres D, Webb CM, Valdez LM, La Rosa M: Severe CoVID-19 during pregnancy and possible vertical transmission. American journal of perinatology 2020, 37:861.

2. Farnoosh G, Alishiri G, Hosseini Zijoud SR, Dorostkar R, Jalali Farahani A: Understanding the Severe Acute Respiratory Syndrome Coronavirus 2 (SARS-CoV-2) and Coronavirus Disease (COVID-19) Based 
on Available Evidence-A Narrative Review. J Mil Med 2020, 22:1-11.

3. Bari E, Ferrarotti I, Saracino L, Perteghella S, Torre ML, Corsico AG: Mesenchymal stromal cell secretome for severe COVID-19 infections: premises for the therapeutic use. Cells 2020, 9:924.

4. Tsuchiya A, Takeuchi S, Iwasawa T, Kumagai M, Sato T, Motegi S, Ishii Y, Koseki Y, Tomiyoshi K, Natsui $\mathrm{K}$ : Therapeutic potential of mesenchymal stem cells and their exosomes in severe novel coronavirus disease 2019 (COVID-19) cases. Inflammation and Regeneration 2020, 40:1-6.

5. Schwartz DA: An analysis of 38 pregnant women with COVID-19, their newborn infants, and maternalfetal transmission of SARS-CoV-2: maternal coronavirus infections and pregnancy outcomes. Archives of pathology \& laboratory medicine 2020, 144:799-805.

6. Mohammadi ZD, Bosaknejad S, Sarvghad S: A survey on the effectiveness of stress management training with cognitive-behavioral group therapy approach on state/trait anxiety, pregnancy anxiety and mental health of primiparous women. Jentashapir Journal of Health Research 2012, 3.

7. Glover V: Maternal depression, anxiety and stress during pregnancy and child outcome; what needs to be done. Best practice \& research Clinical obstetrics \& gynaecology 2014, 28:25-35.

8. Armitage R, Nellums LB: COVID-19 and the consequences of isolating the elderly. The Lancet Public Health 2020, 5:e256.

9. Corbett GA, Milne SJ, Hehir MP, Lindow SW, O'connell MP: Health anxiety and behavioural changes of pregnant women during the COVID-19 pandemic. European Journal of Obstetrics, Gynecology, and Reproductive Biology 2020, 249:96.

10. Masjoudi M, Aslani A, Khazaeian S, Fathnezhad-Kazemi A: Explaining the experience of prenatal care and investigating the association between psychological factors with self-care in pregnant women during COVID-19 pandemic: a mixed method study protocol. Reproductive health 2020, 17:1-7.

11. Ferdous MZ, Islam MS, Sikder MT, Mosaddek ASM, Zegarra-Valdivia J, Gozal D: Knowledge, attitude, and practice regarding COVID-19 outbreak in Bangladesh: An online-based cross-sectional study. PloS one 2020, 15:e0239254.

12. Honarvar B, Lankarani KB, Kharmandar A, Shaygani F, Zahedroozgar M, Haghighi MRR, Ghahramani S, Honarvar H, Daryabadi MM, Salavati Z: Knowledge, attitudes, risk perceptions, and practices of adults toward COVID-19: a population and field-based study from Iran. International journal of public health 2020, 65:731-739.

13. Rasmussen SA, Smulian JC, Lednicky JA, Wen TS, Jamieson DJ: Coronavirus Disease 2019 (COVID19) and Pregnancy: What obstetricians need to know. American journal of obstetrics and gynecology 2020.

14. Fakari FR, Simbar M: Coronavirus pandemic and worries during pregnancy; a letter to editor. Archives of academic emergency medicine 2020, 8:e21-e21.

15. Rezaeian SM, Abedian Z, Latifnejad Roudsari R, Mazloom SR, Dadgar S: The relationship of prenatal self-care behaviors with stress, anxiety and depression in women at risk of preterm delivery. The Iranian Journal of Obstetrics, Gynecology and Infertility 2017, 20:68-76. 
16. Daniel M, Messer LC: Perceptions of disease severity and barriers to self-care predict glycemic control in Aboriginal persons with type 2 diabetes mellitus. Chronic Diseases and Injuries in Canada 2002, 23:130.

17. Tan MY: The relationship of health beliefs and complication prevention behaviors of Chinese individuals with Type 2 Diabetes Mellitus. Diabetes research and clinical practice 2004, 66:71-77.

18. Peacock EJ, Wong PT: The stress appraisal measure (SAM): A multidimensional approach to cognitive appraisal. Stress medicine 1990, 6:227-236.

19. Folkman S, Lazarus RS, Dunkel-Schetter C, DeLongis A, Gruen RJ: Dynamics of a stressful encounter: cognitive appraisal, coping, and encounter outcomes. Journal of personality and social psychology 1986, 50:992.

20. Momeni javid F, simbar m, Dolatian M, Alavi Majd H: Comparison of pregnancy self-care, perceived social support and perceived stress of women with gestational diabetes and healthy pregnant women. Iranian Journal of Endocrinology and Metabolism 2014, 16:156-164.

21. Li J-B, Yang A, Dou K, Wang L-X, Zhang M-C, Lin X-Q: Chinese public's knowledge, perceived severity, and perceived controllability of the COVID-19 and their associations with emotional and behavioural reactions, social participation, and precautionary behaviour: A national survey. 2020.

22. Salkovskis PM, RIMES KA, WARWICK HMC: The Health Anxiety Inventory: development and validation of scales for the measurement of health anxiety and hypochondriasis. Psychological medicine 2002, $32: 843$.

23. Dashraath P, Jeslyn WJL, Karen LMX, Min LL, Sarah L, Biswas A, Choolani MA, Mattar C, Lin SL: Coronavirus disease 2019 (COVID-19) pandemic and pregnancy. American journal of obstetrics and gynecology 2020.

24. Din YM, Munir SI, Razzaq SA, Ahsan A, Maqbool S, Ahmad O: Risk Perception of COVID-19 Among Pregnant Females. Annals of King Edward Medical University 2020, 26:176-180.

25. Yıldırım M, Güler A: COVID-19 severity, self-efficacy, knowledge, preventive behaviors, and mental health in Turkey. Death studies 2020:1-8.

26. Dolatian M, Alavi Majd H: Comparison of pregnancy self-care, perceived social support and perceived stress of women with gestational diabetes and healthy pregnant women. Iranian Journal of Endocrinology and Metabolism 2014, 16:156-164.

27. Rezaeean S-M, Abedian Z, Latifnejad-Roudsari R, Mazloum S-R, Abbasi Z: The Effect of Prenatal Self Care Based on Orem's Theory on Preterm Birth Occurrence in Women at Risk for Preterm Birth. Iranian Journal of Nursing and Midwifery Research 2020, 25:242-248.

28. Roozbeh N, Nahidi F, Hajiyan S: Barriers related to prenatal care utilization among women. Saudi medical journal 2016, 37:1319.

29. Mohammadpour M, Ghorbani V, Khoramnia S, Ahmadi SM, Ghvami M, Maleki M: Anxiety, SelfCompassion, Gender Differences and COVID-19: Predicting Self-Care Behaviors and Fear of COVID-19 Based on Anxiety and Self-Compassion with an Emphasis on Gender Differences. Iranian Journal of Psychiatry 2020, 15:213. 
30. Wang C, Pan R, Wan X, Tan Y, Xu L, Ho CS, Ho RC: Immediate psychological responses and associated factors during the initial stage of the 2019 coronavirus disease (COVID-19) epidemic among the general population in China. International journal of environmental research and public health 2020, $17: 1729$.

31. Anikwe CC, Ogah CO, Anikwe IH, Okorochukwu BC, Ikeoha CC: Coronavirus disease 2019: Knowledge, attitude, and practice of pregnant women in a tertiary hospital in Abakaliki, southeast Nigeria. International Journal of Gynecology \& Obstetrics 2020.

32. Fridman D, Steinberg E, Azhar E, Weedon J, Wilson TE, Minkoff H: Predictors of H1N1 vaccination in pregnancy. American journal of obstetrics and gynecology 2011, 204:S124-S127.

33. Goldfarb I, Panda B, Wylie B, Riley L: Uptake of influenza vaccine in pregnant women during the 2009 H1N1 influenza pandemic. American journal of obstetrics and gynecology 2011, 204:S112-S115.

34. Al-Mohammed HI, Amin TT, Aboulmagd E, Hablus HR, Zaza BO: Prevalence of intestinal parasitic infections and its relationship with socio-demographics and hygienic habits among male primary schoolchildren in Al-Ahsa, Saudi Arabia. Asian Pacific Journal of Tropical Medicine 2010, 3:906-912.

35. Narang S, Khinda VIS, Brar GS, Kallar S: Oral health status and treatment needs among 6, 9 and 12 years old rural and Urban school children in India: An epidemiological survey. Journal of Advanced Oral Research 2016, 7:27-31.

36. Li S, Feng B, Liao W, Pan W: Internet use, risk awareness, and demographic characteristics associated with engagement in preventive behaviors and testing: cross-sectional survey on COVID-19 in the United States. Journal of medical Internet research 2020, 22:e19782.

37. Shiina A, Niitsu T, Kobori O, Idemoto K, Hashimoto T, Sasaki T, Igarashi Y, Shimizu E, Nakazato M, Hashimoto K: Relationship between perception and anxiety about COVID-19 infection and risk behaviors for spreading infection: A national survey in Japan. Brain, Behavior, \& Immunity-Health 2020, 6:100101.

38. Schore JR, Schore AN: Modern attachment theory: The central role of affect regulation in development and treatment. Clinical social work journal 2008, 36:9-20.

39. Pakpour AH, Griffiths MD: The fear of COVID-19 and its role in preventive behaviors. Journal of Concurrent Disorders 2020.

40. Wirtz PW, Rohrbeck CA, Burns KM: Anxiety effects on disaster precautionary behaviors: a multi-path cognitive model. Journal of health psychology 2019, 24:1401-1411.

41. Jones JH, Salathe M: Early assessment of anxiety and behavioral response to novel swine-origin influenza A (H1N1). PLoS one 2009, 4:e8032.

42. Jungmann SM, Witthöft M: Health anxiety, cyberchondria, and coping in the current COVID-19 pandemic: Which factors are related to coronavirus anxiety? Journal of Anxiety Disorders 2020:102239.

43. Tull MT, Barbano AC, Scamaldo KM, Richmond JR, Edmonds KA, Rose JP, Gratz KL: The prospective influence of COVID-19 affective risk assessments and intolerance of uncertainty on later dimensions of health anxiety. Journal of anxiety disorders 2020, 75:102290. 
44. Asmundson GJ, Abramowitz JS, Richter AA, Whedon M: Health anxiety: current perspectives and future directions. Current psychiatry reports 2010, 12:306-312.

\section{Tables}

Table 1. Demographic and obstetrics characteristics of participants and their relationship with self-care and health anxiety 


\begin{tabular}{|c|c|c|c|c|c|c|c|}
\hline $\begin{array}{l}\text { Health } \\
\text { anxiety }\end{array}$ & self-care & $\begin{array}{l}\text { Total } \\
(n=440) \\
N(\%)\end{array}$ & $\begin{array}{l}\text { Khash } \\
(n=98) \\
N(\%)\end{array}$ & $\begin{array}{l}\text { Saravan } \\
(n=112) \\
N(\%)\end{array}$ & $\begin{array}{l}\text { Mirjave } \\
(n=50) \\
N(\%)\end{array}$ & $\begin{array}{l}\text { Zahedan } \\
(n=180) \\
N(\%)\end{array}$ & variable \\
\hline \multicolumn{8}{|c|}{ Age (year) } \\
\hline \multirow[t]{3}{*}{$0.619 *$} & $0.509 *$ & $116(26.4)$ & 33(33.7) & $28(25)$ & $6(12)$ & $49(27.2)$ & $15-24$ \\
\hline & & $213(48.4)$ & $39(39.8)$ & $59(52.7)$ & $31(62)$ & $84(46.7)$ & $25-34$ \\
\hline & & $111(25.2)$ & $26(26.5)$ & $25(22.3)$ & $13(26)$ & $47(26.1)$ & $\geq 35$ \\
\hline \multicolumn{8}{|l|}{ Gravid } \\
\hline \multirow[t]{3}{*}{$>0.010 *$} & $>0.001^{\star}$ & $180(40.9)$ & $36(36.7)$ & $44(39.3)$ & $19(38)$ & $81(45)$ & $1-2$ \\
\hline & & $141(32)$ & $25(25.5)$ & $34(30.4)$ & $16(32)$ & $66(36.7)$ & $3-4$ \\
\hline & & 119(27) & $37(37.8)$ & $34(30.4)$ & $15(30)$ & 33(18.3) & $>4$ \\
\hline \multicolumn{8}{|c|}{ Gestational age (week) } \\
\hline \multirow[t]{3}{*}{$0.279 *$} & $0.110^{*}$ & $80(18.2)$ & 19(19.4) & 18(16.1) & $10(20)$ & 33(18.3) & $\leq 14$ \\
\hline & & $228(51.8)$ & $49(50)$ & $50(44.6)$ & $25(50)$ & $104(57.8)$ & $15-28$ \\
\hline & & 132(30) & $30(30.6)$ & $44(39.3)$ & $15(30)$ & $43(23.9)$ & $\geq 29$ \\
\hline \multicolumn{8}{|c|}{ Educational } \\
\hline \multirow[t]{3}{*}{$0.001 * \star>$} & $0.001^{\star \star}>$ & $329(74.8)$ & $79(80.6)$ & $92(82.1)$ & $46(92)$ & $112(62.2)$ & $\begin{array}{l}\text { Less than } \\
\text { diploma }\end{array}$ \\
\hline & & $111(25.2)$ & 19(14.4) & $20(17.9)$ & $4(8)$ & 68(37.8) & $\begin{array}{l}\text { Diploma or } \\
\text { higher }\end{array}$ \\
\hline & & Spouse ed & ation & & & & \\
\hline \multirow[t]{2}{*}{$0.001^{* \star>}$} & $0.001^{* *>}$ & $213(48.4)$ & $51(11.6)$ & $61(51)$ & $27(23)$ & 74(16.8) & $\begin{array}{l}\text { Less than a } \\
\text { diploma }\end{array}$ \\
\hline & & $227(51.6)$ & $47(48)$ & $51(11.6)$ & $23(5.2)$ & $106(24.1)$ & $\begin{array}{l}\text { Diploma or } \\
\text { higher }\end{array}$ \\
\hline \multicolumn{8}{|c|}{ Occupation } \\
\hline \multirow[t]{2}{*}{$0.001^{* *>}$} & $0.001^{\star \star}>$ & $342(77.7)$ & 84(19.1) & 87(19.8) & $39(8.9)$ & 132(30) & housewife \\
\hline & & $98(23.3)$ & $14(3.2)$ & $25(5.7)$ & $11(2.5)$ & $48(10.9)$ & employed \\
\hline \multicolumn{8}{|c|}{ Spouse occupation } \\
\hline \multirow[t]{2}{*}{$0.863^{\star *}$} & $0.428 * \star$ & $58(13.2)$ & $16(3.6)$ & $11(2.5)$ & $3(0.7)$ & $28(6.4)$ & unemployed \\
\hline & & $382(86.8)$ & $82(18.6)$ & $101(23)$ & $47(10.7)$ & $152(34.5)$ & employed \\
\hline
\end{tabular}




\begin{tabular}{|c|c|c|c|c|c|c|c|}
\hline \multirow[t]{2}{*}{$0.001 * \star>$} & \multirow[t]{2}{*}{$0.001^{\star \star}>$} & $271(61.6)$ & $65(14.8)$ & $81(18.4)$ & $42(9.8)$ & $83(18.9)$ & Yes \\
\hline & & 169(38.4) & $33(7.5)$ & $31(7)$ & $8(1.8)$ & $97(22)$ & No \\
\hline \multicolumn{8}{|c|}{ Reason for not receiving } \\
\hline \multirow[t]{3}{*}{$0.001^{* *>}$} & \multirow[t]{3}{*}{$0.001^{\star \star>}>$} & 138(81.64) & $24(14.20)$ & $29(17.15)$ & $6(3.55)$ & $79(46.74)$ & $\begin{array}{l}\text { Fear of } \\
\text { COVID-19 }\end{array}$ \\
\hline & & $16(9.46)$ & $0(0)$ & $2(1.18)$ & $3(1.78)$ & $11(6.50)$ & uninformed \\
\hline & & 15(8.87) & $7(4.14)$ & $3(1.77)$ & $5(2.95)$ & $0(0)$ & $\begin{array}{l}\text { long } \\
\text { distance }\end{array}$ \\
\hline
\end{tabular}

*.one-way ANOVA

**. Independent-samples T-test

Table2: Means, Standard Deviations and Correlations between the Variables of the Study.

\begin{tabular}{|c|c|c|c|c|c|c|c|c|c|}
\hline & 1 & 2 & 3 & 4 & 5 & Mean & SD & Min & Max \\
\hline 1-Self-care & & $-0.339^{\star *}$ & $0.620^{\star *}$ & $0.236^{* *}$ & $0.475^{\star *}$ & 31.25 & 8.59 & 15 & 50 \\
\hline 2- health Anxiety & & & $-0.325^{\star \star}$ & $0.101^{\star}$ & $-0.316^{\star *}$ & 32.72 & 7.64 & 20 & 54 \\
\hline 3- Knowledge & & & & $0.200^{\star \star}$ & $0.368^{\star \star}$ & 14.15 & 5.08 & 5 & 24 \\
\hline 4- perceived severity & & & & & $0.098^{*}$ & 17.08 & 3.32 & 8 & 25 \\
\hline $\begin{array}{l}\text { 5-perceived } \\
\text { behavioral control }\end{array}$ & & & & & & 40.50 & 10.42 & 15 & 55 \\
\hline
\end{tabular}

${ }^{* *} \mathrm{P}<0.01$

${ }^{*} \mathrm{P}<0.05$

Table 3. Effect of awareness, perceived severity, perceived behavioral control, and demographic characteristics on self-care based on univariate and multivariate linear regression 


\begin{tabular}{|c|c|c|c|c|c|c|c|c|}
\hline$F$ & $95 \% \mathrm{Cl}$ & $\beta$ & S.E & B & $\mathbf{R}^{2}{ }_{\text {adj }}$ & $\mathrm{R}^{2}$ & $\mathbf{R}$ & variable \\
\hline & & & & & & & & Model 1 \\
\hline $273.30^{*}$ & $\begin{array}{l}(0.923 \\
1.172)\end{array}$ & $0.620^{*}$ & 0.063 & 1.047 & 0.383 & 0.384 & 0.620 & knowledge \\
\hline $25.787^{*}$ & $\begin{array}{l}(0.374 \\
0.845)\end{array}$ & $0.236^{*}$ & 0.120 & 0.609 & 0.053 & 0.056 & 0.236 & $\begin{array}{l}\text { Perceived } \\
\text { severity }\end{array}$ \\
\hline \multirow[t]{2}{*}{$127.615^{*}$} & $\begin{array}{l}(0.323 \\
0.460)\end{array}$ & $0.475^{\star}$ & 0.035 & 0.392 & 0.224 & 0.226 & 0.475 & $\begin{array}{l}\text { perceived } \\
\text { behavioral } \\
\text { control }\end{array}$ \\
\hline & & & & & & & & Model 2 \\
\hline \multirow[t]{5}{*}{$126.957^{*}$} & & & & & 0.463 & 0.466 & 0.683 & \\
\hline & $\begin{array}{l}(0.708 \\
0.962)\end{array}$ & $0.494^{*}$ & 0.065 & 0.835 & & & & knowledge \\
\hline & $\begin{array}{l}(0.102 \\
0.465)\end{array}$ & $0.110^{*}$ & 0.092 & 0.283 & & & & $\begin{array}{l}\text { Perceived } \\
\text { severity }\end{array}$ \\
\hline & $\begin{array}{l}(0.172 \\
0.294)\end{array}$ & $0.282^{*}$ & 0.031 & 0.233 & & & & $\begin{array}{l}\text { perceived } \\
\text { behavioral } \\
\text { control }\end{array}$ \\
\hline & & & & & & & & Model 3 \\
\hline \multirow[t]{10}{*}{$83.63^{*}$} & & & & & 0.629 & 0.636 & 0.798 & \\
\hline & $\begin{array}{l}(0.248 \\
0.793)\end{array}$ & $0.330^{*}$ & 0.098 & 0.478 & & & & knowledge \\
\hline & $\begin{array}{l}(-0.064 \\
0.012)\end{array}$ & -0.037 & 0.019 & -0.026 & & & & $\begin{array}{l}\text { Perceived } \\
\text { severity }\end{array}$ \\
\hline & $\begin{array}{l}(-0.010 \\
0.037)\end{array}$ & 0.033 & 0.012 & 0.013 & & & & $\begin{array}{l}\text { perceived } \\
\text { behavioral } \\
\text { control }\end{array}$ \\
\hline & $\begin{array}{l}(-0.239 \\
0.020)\end{array}$ & -0.048 & 0.066 & -0.116 & & & & gravid \\
\hline & $\begin{array}{l}(-0.647 \\
1.065)\end{array}$ & 0.031 & 0.436 & 0.274 & & & & Received care \\
\hline & $\begin{array}{l}(-0.463 \\
0.691)\end{array}$ & 0.018 & 0.295 & 0.115 & & & & $\begin{array}{l}\text { Cause of not } \\
\text { receiving care }\end{array}$ \\
\hline & $\begin{array}{l}\text { (12.596, } \\
17.181)\end{array}$ & $0.753^{*}$ & 1.116 & 14.889 & & & & $\begin{array}{l}\text { Female } \\
\text { education }\end{array}$ \\
\hline & $\begin{array}{l}(-0.373 \\
0.572)\end{array}$ & 0.012 & 0.241 & 0.100 & & & & Male education \\
\hline & $(-0.533$ & 0.004 & 0.287 & $\begin{array}{c}0.030 \\
\text { age } 18 / 21\end{array}$ & & & & Female \\
\hline
\end{tabular}


*; $p<0.01$, Model 1, Unadjusted, Model 2, Adjusted for knowledge, perceived severity, perceived behavioral control., Model 3 Adjusted for knowledge, perceived severity, perceived behavioral control and significant variables in the demographic table

Table 4: Effect of awareness, perceived severity, perceived behavioral control, and demographic characteristics on health anxiety based on univariate and multivariate linear regression 


\begin{tabular}{|c|c|c|c|c|c|c|c|c|}
\hline $\mathbf{F}$ & $95 \% \mathrm{Cl}$ & $\beta$ & S.E & B & $\mathbf{R}^{2}{ }_{\text {adj }}$ & $\mathrm{R}^{2}$ & $\mathbf{R}$ & variable \\
\hline & & & & & & & & Model 1 \\
\hline $51.607^{*}$ & $\begin{array}{l}(-0.621 \\
-0.345)\end{array}$ & $-0.325^{\star}$ & 0.068 & -0.488 & 0.103 & 0.105 & 0.325 & knowledge \\
\hline $4.565^{* \star}$ & $(0.019,0.448)$ & $0.102^{*}$ & 0.109 & 0.234 & 0.008 & 0.010 & 0.102 & Perceived severity \\
\hline \multirow[t]{2}{*}{$48.704^{*}$} & $\begin{array}{l}(-0.297 \\
-0.167)\end{array}$ & $-0.316^{*}$ & 0.033 & -0.232 & 0.098 & 0.100 & 0.316 & $\begin{array}{l}\text { perceived } \\
\text { behavioral control }\end{array}$ \\
\hline & & & & & & & & Model 2 \\
\hline \multirow[t]{5}{*}{$32.127^{*}$} & & & & & 0.175 & 0.181 & 0.425 & \\
\hline & $\begin{array}{l}(-0.553 \\
-0.273)\end{array}$ & $-0.275^{*}$ & 0.071 & -0.413 & & & & knowledge \\
\hline & $(0.212,0.612)$ & $0.179^{*}$ & 0.102 & 0.412 & & & & Perceived severity \\
\hline & $\begin{array}{l}(-0.238 \\
-0.104)\end{array}$ & -0.233 & 0.034 & -0.171 & & & & $\begin{array}{l}\text { perceived } \\
\text { behavioral control }\end{array}$ \\
\hline & & & & & & & & Model 3 \\
\hline \multirow[t]{10}{*}{$13.93^{*}$} & & & & & 0.297 & 0.313 & 0.462 & \\
\hline & $\begin{array}{l}(-0.934 \\
-0.423)\end{array}$ & $-0.206^{*}$ & 0.130 & -0.679 & & & & knowledge \\
\hline & $(0.313,0.518)$ & 0.292 & 0.052 & 0.416 & & & & Perceived severity \\
\hline & $\begin{array}{l}(-0.629 \\
0.125)\end{array}$ & -0.052 & 0.119 & -0.252 & & & & $\begin{array}{l}\text { perceived } \\
\text { behavioral control }\end{array}$ \\
\hline & $\begin{array}{l}(-0.553 \\
0.191)\end{array}$ & -0.038 & 0.189 & -0.181 & & & & gravid \\
\hline & $\begin{array}{l}(-1.818, \\
3.123)\end{array}$ & 0.037 & 1.257 & 0.652 & & & & Received care \\
\hline & $\begin{array}{l}(-0.681 \\
2.659)\end{array}$ & 0.076 & 0.850 & 0.989 & & & & $\begin{array}{l}\text { Reason for not } \\
\text { receiving }\end{array}$ \\
\hline & $\begin{array}{l}(-11.218 \\
-5.108)\end{array}$ & $-0.362^{*}$ & 1.554 & -6.163 & & & & $\begin{array}{l}\text { Female } \\
\text { educational }\end{array}$ \\
\hline & $\begin{array}{l}(-2.369 \\
0.359)\end{array}$ & -0.059 & 0.694 & -1.005 & & & & Male education \\
\hline & $\begin{array}{l}(-2.864 \\
0.392)\end{array}$ & 0.061 & 0.828 & -1.236 & & & & $\begin{array}{l}\text { Female } \\
\text { occupation }\end{array}$ \\
\hline
\end{tabular}

*; $p<0.01$, **; $p<0.05$ Model 1, Unadjusted, Model 2, Adjusted for knowledge, perceived severity, perceived behavioral control., Model 3 Adjusted for knowledge, perceived severity, perceived behavioral control and 
significant variables in the demographic table

Page 21/21 